\title{
LA CIUDAD DE MÉXICO Y EL DISTRITO FEDERAL: UN ANÁLISIS POLÍTICO-CONSTITUCIONAL
}

\author{
The City of Mexico and the Federal District: \\ a political-constitutional analysis
}

\author{
Javier Hurtado González ${ }^{1}$ \\ Profesor-Investigador del CUCSH \\ Universidad de Guadalajara (México) \\ docjhurtado@hotmail.com
Alberto Arellano Ríos ${ }^{2}$
Profesor-investigador
El Colegio de Jalisco (México) aarellano@coljal.edu.mx

RESUMEN: Este artículo hace una reflexión sobre el estatuto y el diseño constitucional de la Ciudad de México y el Distrito Federal. Realiza un análisis de las fases en las que han estado inmersos ambos entes y se detiene en el debate sobre la reforma política de la capital mexicana. En este punto se esbozan y estudian con detalles las iniciativas de reforma constitucional presentadas.

PALABRAS CLAVE: Ciudad de México. Distrito Federal. Reforma y diseño constitucional.

ABSTRACT: East article does a reflection on the statute and the constitutional design of the Mexico City and the Federal District. It's realizes an analysis of the phases in which both entities have been immersed and stops in the debate on the political reform of the Mexican capital. In this point there are outlined and study by details the initiatives of constitutional reform presented.

KEY WORDS: Mexico City. Federal District. Reform and constitutional design.

1 Doctor en Ciencias Sociales por la Universidad de Guadalajara. Miembro del Sistema Nacional de Investigadores. Autor de una decena de libros y capítulos de libros, así como diversos artículos en diferentes revistas académicas. Tiene diversos reconocimientos en México. Sus temas de estudio e interés son los sistemas de gobierno, en particular el presidencialismo mexicano, así como el estudio de las elites, los partidos y asociaciones políticas. Artículo recibido el 23 de junio y aprobado el 28 de octubre de 2009.

2 Doctor en Ciencias Sociales por el Centro de Investigaciones y Estudios Superiores en Antropología Social. Sus temas de estudio e interés son los Poderes Judiciales en particular el de Jalisco, así como el estudio y análisis de actores e instituciones en los procesos de cambio político. Ha escrito diversos artículos en revistas especializadas sobre estos tópicos. 


\section{INTRODUCCIÓN ${ }^{3}$}

La senadora María de los Ángeles Moreno planteó en septiembre del año 2008 que en México ya había suficiente material, tanto del derecho y la política comparada como iniciativas presentadas en el Congreso de la Unión, para adecuar o mejorar el estatuto político-constitucional de la capital de nuestro país. ${ }^{4}$ En otros espacios y documentos, por nuestra parte hemos planteado, y como resultado de un análisis de política comparada, que el mejor u óptimo diseño para la capital mexicana consistiría en erigirla en una ciudad-estado a la manera de algunas ciudades alemanas y Buenos Aires, Argentina. Un cambio constitucional de esta envergadura sería una reforma de largo alcance o gran calado, pero que resolvería muchos de los problemas de gobernabilidad que hay en las relaciones entre las autoridades capitalinas y las nacionales.

Sin embargo, por lo que toca a este texto, nos ocupamos de esbozar y evaluar con detalle el material que los actores y partidos políticos han presentado en el Congreso mexicano. Es un artículo cuya fortaleza reside en el estudio de fuentes de primera mano. Al mismo tiempo de que el documento es un estudio de coyuntura y se inserta en el debate que hay sobre la reforma del Estado en nuestro país. Más aún cuando el tema del Distrito Federal y la Ciudad de México no fueron un tema relevante y toral en los foros y las mesas de consulta. Con excepción, claro está, de los actores de la capital del país. ${ }^{5}$

Ante este vacío en abril de 2007 el pleno del Senado aprobó el dictamen del "Grupo de Trabajo Interparlamentario para la Concertación de la Reforma Política del Distrito Federal". En dicha instancia, participarían senadores, diputados federales y de la capital de todos los partidos, además se señalaban diversos mecanismos y procedimientos, así como grupos de trabajo temáticos para discutir y trabajar la reforma. ${ }^{6}$

3 Este artículo forma parte de una investigación más amplia titulada: "La Ciudad de México no es el Distrito Federal: Estatuto Político y Diseño Institucional”, y su contenido corresponde esencialmente al capítulo cuarto. El documento aún es inédito.

4 Moreno, María de los Ángeles (2008): ¿Un alcalde para la Ciudad de México?”, en Examen (Año XIX, Núm. 163, septiembre): pp. 48-49.

5 No se puede dejar de mencionar la vasta cantidad de iniciativas presentadas en el Congreso de la Unión con relación a la capital del país, lo cual contrastó con las presentadas en los foros convocados en 2007 para la Reforma del Estado. El ejemplo más claro fue el de la mesa sobre federalismo en dónde se presentó sólo una iniciativa que implicó concisamente al Distrito Federal. No es posible que la discusión sobre el sistema de organización política esté ausente el debate sobre las características fundamentales de la capital del Estado nacional. Además, se debe señalar que la ponencia se limitó a una reforma político-electoral: los temas fueron sobre propaganda, campañas, acceso de los partidos políticos y los candidatos a los medios de comunicación. La iniciativa, en tanto ponencia, fue presentada el 20 de junio de 2007 a las 19:06 horas por Aminadab Rafael Pérez Franco, siendo ésta la única exposición en el foro sobre federalismo, celebrada en la ciudad de Guadalajara.

6 Las cincos mesas de trabajo temático fueron: 1. Rediseño Constitucional del Distrito Federal; 2. Replanteamiento Constitucional de la Coexistencia de los Poderes Federales y Órganos Locales de Gobierno; 3. Estructura y Marco de Atribuciones Básico del Gobierno Local; 4. Bases Electorales y de Participación Ciudadana y Vecinal; y 5. La Visión y operación Metropolitana. Moreno, María de los Ángeles (2008), op. cit., pp. 48-49. 
Y pese a que una de las cámaras legislativas intentó resarcir la falla ante un tema nodal, el 8 de mayo de 2007 la Comisión de Gobierno de la Asamblea Legislativa del Distrito Federal determinó elaborar una propuesta propia de reforma política para el Distrito Federal "luego de que este tema ha sido abandonado y marginado de las negociaciones que a nivel federal sostienen los partidos políticos con miras a la Reforma del Estado". 7

Cabe precisar que si este artículo es un estudio de coyuntura y del acontecer, su significado histórico se adquiere si se amplía la mirada temporal y espacial. ${ }^{8}$ En este sentido, el texto se estructura en dos grandes apartados. En el primero se hace un recuento de las fases político-constitucionales en las que ha estado inmersa la Ciudad de México y el Distrito Federal. Es una visión desde del derecho constitucional en una historia de larga duración. Las fases reconocidas en términos jurídico-institucionales son diez.

La segunda corresponde al análisis de las iniciativas presentadas en el Congreso de la Unión. Es el debate actual que se sitúa desde el año de 1997 al año de 2009, y consiste en el intervalo en el que no se ha modificado la Constitución en lo relativo a las características fundamentales de la capital mexicana. Para la consecución de este fin se analizan 43 iniciativas que, consideramos, tocan aspectos fundamentales del Distrito Federal o la Ciudad de México. No obstante, salta la inquietud de por qué detenerse a su estudio. Sobre este punto simplemente se puede señalar simplemente que en ellas se observa cómo los actores y los partidos políticos conceptualizan un problema y pretenden resolverlo.?

\section{LAS EXPRESIONES POLÍTICO-CONSTITUCIONALES DE LA CAPITAL MEXICANA}

\subsection{La fase de la Constitución de 1824}

Consumada la independencia de México, y al momento de discutirse en la Constitución Política de 1824 la formación de la federación mexicana, se discutía al mismo tiempo el estatus y las características de la capital del nuevo estado nacional. Pero este tema pareció haber tomado por sorpresa a una parte de los constituyentes, en tanto que en otros el tema estaba resuelto y no merecía mayor discusión porque de facto se dejaron guiar por el hecho de que la Ciudad de México había sido la capital de la

Véase (2007) "Realzan reforma del DF ante abandono en el ámbito federal”, en La Jornada (mayo 9). Anteriormente se había suscrito el Acta de la Cuarta Reunión de la Comisión del Distrito Federal, foro para la Reforma del Estado, celebrada el 6 de febrero de 2007.

8 LeÓn Portilla, Miguel (2003): La construcción de significado en la Historia (Zapopan, editado por El Colegio de Jalisco).

9 En este sentido en las iniciativas podemos observar la reflexión constitucional como un fenómeno de políticas públicas o de Estado. Véase Aguilar Villanueva, Luis F. (1991): "Estudio introductorio". Problemas públicos y agenda de gobierno, (Ciudad de México, Miguel Ángel Porrúa editores), pp. 15-72. 
nación mexicana, con ello trataron de evitar una profunda discusión de la su naturaleza constitucional.

En tal virtud el Constituyente simplemente se limitó a señalar en la carta constitucional que el Congreso general tuviera la atribución de rotular el lugar en donde debían residir los poderes de la naciente federación. De esta manera, el debate se centró en lo relativo al lugar, más que en lo relacionado al régimen jurídico y competencial de la nueva entidad.

Así hubo dos posiciones encontradas: los que estaban a favor de que los poderes federales se trasladaran a Querétaro y los que estaban en pro de que éstos residieran en la Ciudad de México. Las discusiones se dieron desde el momento mismo de la elaboración del dictamen respectivo que sería puesto a la consideración del pleno del Congreso. En este debate de alguna manera se reflejaron las incipientes disputas ideológicas entre liberales y conservadores o entre federalistas y centralistas. Los primeros estaban a favor de que la capital se trasladara a la ciudad de Querétaro, mientras que los segundos se pronunciaban en pro de la Ciudad de México. ${ }^{10}$

Los segundos partieron del supuesto de que el establecimiento de los poderes federales en un Distrito Federal localizado en la ciudad de Querétaro era doblemente liberal y federal. Por un lado por el concepto mismo de esta figura político-administrativa y por el otro de que la ubicación de la capital del nuevo Estado nacional era una manifestación en favor del federalismo y la descentralización. Argumentaron que la Ciudad de México tenía todos los elementos centralizadores propuestos por los conservadores. Y aunque los debates fueron intensos e interesantes, ${ }^{11}$ una parte de los liberales, término votando a favor porque la Ciudad de México fuera la capital del país. Quizá por estas razones el destacado conservador Fray Servando Teresa de Mier reconocía: "proponíamos un gobierno federal en el nombre, y central en la realidad". ${ }^{12}$

Empero, el proceso para crear dentro de la Ciudad de México un Distrito Federal que fuera sede de los Poderes Federales, no sólo estuvo caracterizado por estas variaciones ideológicas entre los diputados constituyentes, sino que también por un accidentado proceso jurídico-constitucional y conceptual al que enseguida nos referiremos de manera sucinta:

Primero. El proyecto de constitución de 1824 sostenía que "sólo se podía establecer la capital federal en un lugar que no fuera la capital de un estado, lo que excluía a

10 El primer grupo fue encabezado por el Diputado José María Becerra y por el Ministro de Relaciones Exteriores Lucas Alamán. El segundo grupo que eran de la idea de trasladar la capital a la ciudad de Querétaro fueron los diputados Miguel Ramos Arizpe, Juan Ignacio Godoy, Valentín Gómez Farías, y José de Jesús Huerta.

11 Véase Gortari, Hiridia de y Hernández Franyutı, Regina (1988): La Ciudad de México y el Distrito Federal. Una historia compartida, (Ciudad de México, editado por el Departamento del Distrito Federal-Instituto Mora, Ciudad de México), pp. 4-5.

12 Citado en McGowan, Gerard Louis (2005): El Distrito Federal de dos leguas, o como el estado de México perdió su capital, (Zinacantepec, editado por El Colegio Mexiquense), p. 16. 
la Ciudad de México, capital del estado del mismo nombre, y también a Querétaro, pues ya era estado". ${ }^{13}$ Esto era lo más recomendable si consideramos la experiencia histórica y la más elemental lógica: en los Estados Unidos, el Distrito de Columbia no se estableció en ninguna ciudad, ni mucho menos en la capital de los estados de Virginia y Maryland que fueron los que cedieron el territorio: originalmente fueron 100 millas cuadradas; $y$, por otro lado, si se creaba una capital federal en la capital de un estado se obligaba a que dicho estado encontrara una nueva capital; o bien, en el caso extremo que el estado debiera desaparecer. ${ }^{14}$

Segundo. El 18 de junio de 1824, el Congreso Constituyente eliminó la restricción de que la nueva capital federal no fuera la capital de uno de los estados, con lo que el camino quedaba abierto para que poco después se le diera cabida a los poderes federales en la Ciudad de México.

Tercero. La determinación de elegir a la Ciudad de México como sede de los poderes federales, era una atribución que la Constitución de 1824 daba a su Congreso Nacional Ordinario y no al Constituyente Permanente, que fue el órgano que finalmente tomó la decisión.

Cuarto. Como la creación del Distrito Federal dentro de la Ciudad de México (capital en ese entonces del Estado de México) en los hechos significaba crear una nueva entidad federativa dentro de un estado ya existente, entonces el procedimiento debió haber sido de que además que fuera una atribución del Congreso Permanente Ordinario, esa decisión, de acuerdo a la constitución, debía producirse mediante una mayoría calificada de ambas Cámaras y de los Estados de la Federación, y no por mayoría absoluta de un Congreso Constituyente como se realizó.

Quinto. La atribución concedida por la Constitución al Congreso para señalar el lugar en que deben residir los poderes de la federación generó controversia, ya que para el Constituyente del Estado de México:

“la palabra lugar de residencia no podía significar 'otra cosa que un terreno' (...) [ya en los debates del Congreso] el diputado Becerra expuso que ni la Ciudad de México ni capital alguna podían considerarse como un 'lugar', término que sólo debía definirse como 'una población entre pueblo y aldea', pues a su parecer no era posible que la capital tuviera más habitantes que varios estados. En consecuencia se debía elegir un lugar más o menos despoblado, lo que concordaba con la afirmación del diputado Lombardo, quien había señalado que la capital de Norteamérica se había fundado en un terreno baldío. (...) [Sin embargo, para la mayoría de los diputados] 'lugar' podía referirse a cualquier punto geográfico del territorio nacional". ${ }^{15}$

13 McGowan, Gerard Louis (2005), Ibíd, p. 18.

14 Algunos de estos supuestos se cumplieron cuando con el correr del tiempo, el Estado de México perdió su capital y tuvo que establecerla en la ciudad de Toluca. Además el Estado de México perdió entre 1824 y 1871 "86 mil 521 kilómetros cuadrados de los 107 mil 619 originales".

15 McGowan, Gerard Louis (2005), Ibíd., p. 35. 
Y sexto. Uno de los argumentos utilizados en contra de que la Ciudad de México no fuera sede del Distrito Federal fue el relativo al costo que implicaría el traslado de los poderes federales a otro lugar distinto. Sin embargo, no se tomó en cuenta el costo del traslado de la capital del Estado de México a otro sitio los que en el fondo eran similares a los que podrían haber generado el traslado de la capital nacional a la ciudad de Querétaro. ${ }^{16}$

No obstante, el 18 de noviembre de 1824 "por votación nominal de 52 diputados a favor y 32 en contra se declaró a la Ciudad de México capital federal pese a las justificadas reclamaciones del estado, del Ayuntamiento y de 32 diputados federales". ${ }^{17}$ A partir de ahí, la Ciudad de México sería la residencia de los Supremos Poderes de la Federación, con un distrito que se extendería en un círculo con un radio de dos leguas a partir del zócalo de la ciudad, territorio que estaría bajo la autoridad de un gobernador nombrado por el Ejecutivo Federal.

\section{EL DISTRITO FEDERAL DE DOS LEGUAS}

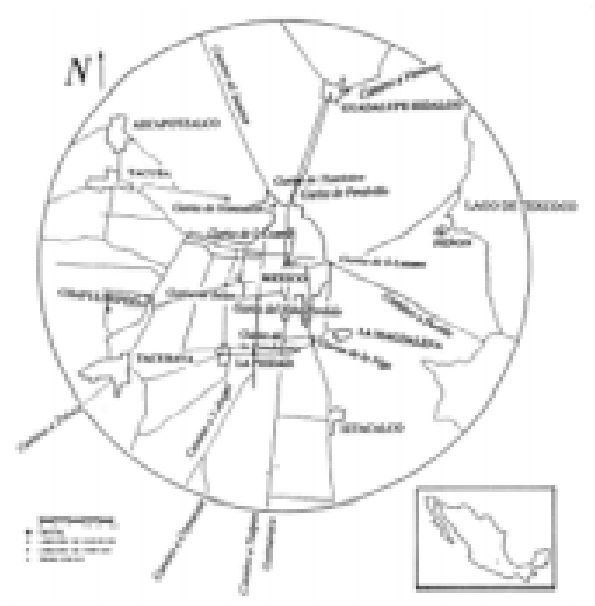

Fuente: McGowan, Gerard Louis (2005): El Distrito Federal de dos leguas, o como el estado de México perdió su capital, (Zinacantepec, editado por El Colegio Mexiquense), p. 20.

16 (...) el Secretario de Justicia habló del enorme costo del traslado de los supremos poderes fuera de la Ciudad de México que, en opinión del Secretario de Hacienda, rebasaría los 700,000 pesos, sin tomar en cuenta el traslado de los empleados y sus familias ni la habilitación de una nueva capital. McGowan, Gerard Louis (2005), Ibíd., p. 25.

17 McGowan, Gerard Louis (2005), Ibíd., p. 38. 
Adicional a lo anterior un problema más fue el que la Constitución federal, recién aprobada, omitiera hacer mención alguna a los ayuntamientos como gobiernos de los municipios por considerar que esto era asunto de la competencia del régimen interior de los estados. En el caso del naciente Distrito Federal y de los ayuntamientos y pueblos en él comprendidos: "las disposiciones relativas a la formación de ayuntamientos constitucionales de mayo y julio de $1812 " .{ }^{18}$

Fue así como el Distrito Federal de dos leguas de radio duró, en su primera época, el mismo tiempo que la primera República federal: 12 años. Pero el 30 de diciembre de 1836, el gobierno centralista dio a conocer la Ley de división del territorio mexicano en departamentos, por la cual la capital del Departamento de México era la ciudad de este nombre. Ante este acontecimiento Toluca dejaba de ser capital formalmente. ${ }^{19}$

Conviene destacar que con las Bases y Leyes Constitucionales de la República Mexicana de 1836, el gobierno interior de los departamentos quedaba a cargo de los gobernadores; y éstos a su vez estaban sujetos al gobierno central por quien eran nombrados a propuesta en terna de las Juntas Departamentales. ${ }^{20}$

En esta circunstancia, de acuerdo a la Ley de División del Territorio Mexicano en Departamentos, la Ciudad de México es restituida al Departamento de México y reasumió su carácter de capital de esa localidad; y, además, reunió la calidad de ser capital de la República mexicana. En esta situación la Ciudad de México abrigaba la peculiaridad de ser capital en sentido doble: de un Departamento y del Estado-nación. Dicha situación duró dos años.

Para 1847, la República federal había vuelto y, por lo tanto, el Distrito Federal de dos leguas se restableció. La Ciudad de México volvió a ser capital federal y los pode-

18 Véase Marván LABORde, Ignacio (2001): "La cuestión del gobierno representativo en el Distrito Federal”, en Cuestiones Constitucionales (Núm. 4, enero-junio): pp. 49-83. Además cabe decir que el recién creado Distrito Federal tenía ayuntamientos. A esto agréguese que una ciudad que era capital de un estado se convierte en Distrito Federal y luego esa ciudad tiene ayuntamientos y uno de esos es precisamente el de la Ciudad de México. Por otro lado, si algo puede decirse respecto a la creación del Distrito Federal, siguiendo de nueva cuenta a McGowan es que el hecho de que la capital fuera la Ciudad de México se debió a una decisión cuya naturaleza fue estrictamente pragmática; y, paradójicamente, de criterios eminentemente centralizadores, ya que se partió del hecho de reconocer que la Ciudad de México era el centro político, económico, religioso, militar, industrial, financiero y cultural del naciente país; y, además, como dijera Fray Servando Teresa de Mier "la ciudad más bella del mundo" (en aquel entonces) McGowan, Gerard Louis (2005), op. cit.

19 Dublán, Manuel y José María Lozano (2004): La Legislación Mexicana. (Ciudad de México, editada por la SCJN-Tribunal Superior del Estado de México-El Colegio de México-Escuela Libre de Derecho): t. 3, p. 253.

20 Las Juntas Departamentales se integraban por siete individuos, elegidos por los mismos electores que nombraban a los diputados para el Congreso; y, en las capitales de los Departamentos y en los puertos con más de "cuatro mil almas" y en los pueblos con más de ocho mil, los ayuntamientos serán elegidos popularmente. Como es de comprenderse, la Ciudad de México era una municipalidad gobernada por un ayuntamiento elegido por votación popular, que existía dentro de un Departamento sujeto a la autoridad de un gobernador designado por el gobierno central. 
res del Estado de México regresaron nuevamente a Toluca. Sin embargo, para 1842 el centralismo reapareció una vez más haciendo posible el regreso de Antonio López de Santa Anna al poder, el 12 de abril de 1853. A partir de entonces el Distrito Federal cambió de nombre al de Distrito de México. La Ciudad de México quedó entonces como capital nacional y el Estado de México se llamó Departamento y sus autoridades se quedaron en la ciudad de Toluca. ${ }^{21}$

Es en este periodo, en el que el original Distrito Federal de dos leguas es modificado por primera vez, se amplió su territorio de manera considerable. ${ }^{22}$ Además de que poco tiempo después, el 25 de noviembre de 1855, el presidente interino de la República, Juan Álvarez, incorporó la localidad de Tlalpan, pues allá fijó su residencia por la desconfianza que tenía del ambiente de la Ciudad de México. "De esta manera la capital se acercó a la residencia presidencial y el Distrito Federal creció en 1,173 km² y 50,000 habitantes. El Distrito Federal de dos leguas había dejado de existir, pero a costa, una vez más, del Estado de México". ${ }^{23}$

\subsection{La fase de la Constitución de 1857}

Con el triunfo de los liberales se restableció el federalismo, y con ello se volvió a discutir dónde deberían residir los poderes federales. El resultado de las discusiones fue el establecimiento del Estado del Valle de México como parte integrante de la federación, con un territorio mayor que el actual, pero se condicionó la existencia de este estado al supuesto de que fueran trasladados a otro lugar los poderes federales. Mientras que en el tema del Distrito Federal y su gobierno interior, se estableció que los ayuntamientos existentes en su territorio, particularmente el de la Ciudad de México, debieron integrarse por medio de elección popular. ${ }^{24}$

Sin embargo, conviene destacar que la Constitución de 1857 "omitió toda comparación o identificación del Distrito Federal con los estados de la unión en cuanto a su organización interna, y simplemente autorizó al Congreso para el arreglo interior de este órgano y los demás territorios federales. ${ }^{25}$ Es así como de la Constitución de 1857, y de su artículo 46, data el principio de que "el Estado del Valle de México se formará del territorio que en la actualidad comprende el distrito Federal; pero la erección sólo tendrá efecto, cuando los Supremos Poderes Federales se trasladen a otro lugar". ${ }^{26}$

\footnotetext{
21 McGowan, Gerard Louis (2005), op. cit., p. 42.

22 Véase el Decreto del 16 de febrero de 1854. Se incluyó a los poblados de San Cristóbal Ecatepec, Tlalnepantla, Los Remedios, San Bartola, Santa Fe, Nixcoac, San Ángel, Coyoacán, Tallpan, Tepepan, Xochimilco, Iztapalapa, El Peñón Viejo y hasta la medianía de las aguas de Texcoco.

23 McGowan, Gerard Louis (2005), op. cit., p. 42.

24 Marván Laborde, Ignacio (2001), op. cit., passim.

25 Tena Ramírez, Felipe (1997): Derecho constitucional mexicano, (Ciudad de México, editado por Porrúa), P. 309.

26 Tena Ramírez, Felipe (1997), Ibíd., p. 614.
} 
Cabe destacar que la Constitución de 1857 no se menciona nada acerca de la Ciudad de México ni de la residencia de los poderes federales. Sin embargo, durante este periodo, nos dice Ignacio Marván que el Congreso sancionó el convenio mediante el cual se establecieron los límites y el territorio actual del Distrito Federal. Mediante una reforma constitucional de 1901 , se suprimió la elección popular de los ayuntamientos y de las autoridades judiciales de la capital; y en 1903 se promulgó la Ley de Organización Política y Federal del Distrito Federal, en la cual el Congreso determinó que el orden administrativo, político y municipal dependería del Presidente por conducto de la Secretaría de Gobernación. ${ }^{27}$

Fue así como poco después del triunfo de la Revolución mexicana de 1910, Venustiano Carranza en su calidad de primer jefe del ejército constitucionalista, presentó su proyecto de Constitución ante el Congreso Constituyente el 1 de diciembre de 1916. En el artículo 43 se propuso, y se señaló, cuáles eran las partes integrantes de la federación. La iniciativa enunció los estados de la A a la Z, para después de finalizada la lista con el estado de Zacatecas mencionar al Distrito Federal y los territorios federales de Baja California y territorio de Quintana Roo. El Constituyente de 1917 aprobó tal y como lo presentó Carranza. Dicha situación prevaleció hasta 1934 cuando, mediante decreto publicado en el Diario Oficial, se suprimieron los territorios de Baja California Sur y Quintana Roo para incluirse en el listado de los estados. ${ }^{28}$

Por otro lado, conviene destacar la propuesta de texto de artículo 44 constitucional presentada también por Carranza al Constituyente de 1917, decía que el Distrito Federal se compondrá del territorio que tenía, más el de los distritos de Chalco, Amecameca, Texcoco, Otumba, Zumpango, Cuautitlán y la parte de Tlalnepantla que queda en el valle de México. Con ello fijaba el lindero con el Estado de México sobre los ejes orográficos de las crestas de las serranías del monte alto y monte bajo. ${ }^{29}$

27 Marván LabORDE, Ignacio (2001), op. cit.

28 De esto se deduce que para Carranza el Distrito Federal era un estado (aunque lo pusiera después que Zacatecas) y no un territorio como los dos que en ese entonces existían.

29 Obsérvese que esta es la primera vez que se pretende llevar a un artículo constitucional el territorio del que a partir de decretos y desmembraciones se había adjudicado el Distrito Federal en detrimento del Estado de México; y, por otro lado, que Carranza pretendía elevar a rango constitucional de manera específica y detallada todos los demás territorios que quería anexarle adicionalmente a los que ya se había apropiado desde 1824 hasta 1916. Como seguramente Carranza presentía que su proyecto concerniente al Distrito Federal no sería aprobado, el 26 de enero de 1917, la Comisión de División Territorial dio a conocer las razones del Primer Jefe del Ejército Constitucionalista para pedir la creación de un Distrito Federal "ensanchado" a todo el Valle de México. Su presentimiento lo manifestó a la comisión de la siguiente manera: "el mismo C. Primer Jefe ha manifestado a esta comisión su vehemente deseo de que, si el Congreso no acepta su propósito, conste, cuando menos, en los archivos del mismo y se haga presente en los debates la intención que a él lo ha inspirado (...) los propósitos del C. Primer Jefe son militares, políticos y civiles (...) haciendo del Valle una circunscripción distinta independiente, esto es, una entidad con sus límites propios, con sus recursos propios, con su administración propia”. 


\subsection{La fase de la Constitución de $1917^{30}$}

El proyecto de Carranza no fue aprobado y el 5 de febrero de 1917 el Constituyente votó favorablemente el siguiente texto del artículo 44 constitucional:

...el Distrito Federal se compondrá del territorio que actualmente tiene y en el caso de que los Poderes federales se trasladen a otro lugar se erigirá en el Estado del Valle de México, con los límites y extensión que le asigne el Congreso General. (Este texto permaneció en vigor hasta el 25 de octubre de 1993).

En cuanto a lo que tiene que ver con la organización legislativo-organizativa del Distrito Federal, la Ley de Organización del Distrito y Territorios Federales, publicada escasos dos meses después de que fuera aprobada la Constitución de la República, se puede decir lo siguiente:

1. Es una ley básicamente de punto estructural, ya que sus primeros cuatro capítulos tienen que ver con autoridades y órganos de gobierno, aparte de un capítulo adicional dedicado al presidente municipal;

2. Es una ley destinada a hacer evidente el sometimiento del gobernador del Distrito Federal al presidente de la República: la fracción tercera de su artículo $6^{\circ}$ señalaba como una de las obligaciones de este funcionario debía "cumplir las órdenes y resoluciones del Presidente de la República";

3. No obstante, paradójicamente, la fracción II del artículo $7^{\circ}$ establecía como una de las facultades del gobernador del Distrito Federal "tener el mando supremo de la policía de la ciudad o población donde resida y de la policía de seguridad de todo el Distrito Federal o territorio respectivo";

4. La ley de referencia establecía en su artículo 45 que "el municipio libre es la base de la división territorial y de la organización política y administrativa del Distrito Federal y de los territorios de la federación"; y que, los ayuntamientos estarían a cargo de un ayuntamiento integrado por miembros de elección popular directa quienes-de conformidad al artículo 60 de la mencionada ley- "todos los años, en la primera sesión del mes de enero cada ayuntamiento nombrara entre sus miembros un presidente y un vicepresidente, que durarán en su encargo hasta el último día de diciembre del mismo año, no pudiendo ser reelectos sino después de haber pasado un año";

5. Por lo que respecta al Ministerio Público, esta ley establecía que el procurador del Distrito Federal sería nombrado y removido por el presidente de la República; y

30 Las leyes y reformas que en adelante se enuncian tienen como base la sección de "Reformas Constitucionales en Orden Cronológico” de la página web: http://www.diputados.gob.mx/LeyesBiblio/ref/ cpeum_crono.htm

31 Esta disposición contrasta de forma ostensible con las disputas que en torno al nombramiento del funcionario que tenga el mando directo de la policía en la Ciudad de México, se dan entre el presidente de la República y el actual jefe de gobierno del Distrito Federal. 
6. Finalmente, el artículo 95 de esa ley le concedía al Gobernador del Distrito Federal inmunidad absoluta; ya que, sólo podía ser procesado por delitos del orden común si previamente el Tribunal Superior del Distrito, "en acuerdo pleno" resolvía "que hay datos bastantes para proceder contra dicho funcionario".

\subsection{La fase de la reforma legal de la Ley Orgánica del Distrito y los Territorios Federales (31 de diciembre de 1928)}

En abril de 1928 el caudillo de la Revolución mexicana: Álvaro Obregón, y formalmente jugando el rol de candidato a la presidencia de la República, envió al Congreso de la Unión una iniciativa de reforma a la ley anterior. La iniciativa inmediatamente fue hecha suya por los diputados del Distrito Federal. En ella se solicitaba a la Comisión Permanente que convocara al Congreso general a un período extraordinario y se estudiara y discutiera su iniciativa.

Corridos los trámites correspondientes, y después del asesinato del caudillo sonorense, la iniciativa fue publicada el 31 de diciembre de 1928 conocida como la Ley Orgánica del Distrito y los Territorios Federales. De esta Ley se destaca lo siguiente:

1. La parte inicial, y con mucho la más voluminosa, es la relativa a la de la extensión y la división político-territorial del Distrito Federal.

2. En su artículo primero establece que el Distrito Federal tiene la extensión y límites fijados por los decretos, de 15 y 17 de diciembre de 1898 . Su artículo segundo establece que el territorio del Distrito Federal se divide en un "Departamento Central" y trece Delegaciones; ${ }^{32}$ el artículo tercero precisa que el Departamento Central estará formado por "las que fueron municipalidades" de México, Tacuba, Tacubaya y Mixcoac (lo cual significa que en 1928 terminó la vida municipal en la Ciudad de México y el Distrito Federal).

3. A lo largo de sus primeros 20 artículos se establecen polígonos y demarcaciones, para el Departamento Central y cada una de las 13 delegaciones, con la mayor precisión posible contemplando calles, cruces, vías de ferrocarril, puentes, montes, canales y demás enunciaciones necesarias para legalizar las apropiaciones que el Congreso de la Unión hacía en favor del Distrito Federal.

4. Se crea la figura de Departamento Central que tendrá por cabecera la Ciudad de México que a partir de ahí se anexa la Ciudad de Tacubaya y las Villas de Tacuba y Mixcoac.

5. Tratándose de la parte estructural esta ley establecía que el Gobierno del Distrito Federal estaría a cargo del presidente de la República, "quien lo ejercerá por medio del Departamento del Distrito Federal”.

32 Las Delegaciones eran, Guadalupe Hidalgo, Azcapotzalco, Ixtacalco, General Anaya, Coyoacán, San Ángel, La Magdalena Contreras, Cuajimalpan, Tlalpan, Ixtapalapa, Xochimilco, Milpa Alta, y Tláhuac. 
6. El Jefe del Departamento del Distrito Federal sería un funcionario nombrado y removido por el Ejecutivo de la Unión.

La ley comenzó a regir el día primero de 1929 y en esa fecha los ayuntamientos que hasta entonces existían hicieron entrega del Ejecutivo de la Unión, a través del Jefe del Departamento del Distrito Federal, de los bienes y oficinas que habían estado a su cargo. De lo anterior se deduce que resultó a todas luces contradictorio que un gobierno federal creara ya no sólo departamentos como sistema de organización político-administrativo sino que, además, en este caso el departamento se denominará "central": la más grande aberración que pueda existir en un sistema federal.

\subsection{La reforma legal de la Ley Orgánica del Departamento del Distrito Federal (31 de diciembre de 1941)}

La Ley Orgánica del Departamento del Distrito Federal, ${ }^{33}$ reiteró y estableció que la función legislativa del Distrito Federal quedaba a cargo del Congreso de la Unión; y que, el presidente de la República tuviera a su cargo el gobierno del Distrito Federal por conducto del Jefe del Departamento del Distrito Federal. Además por primera vez estableció los límites precisos de la Ciudad de México en su artículo noveno. En ella el Distrito Federal quedó dividido en la Ciudad de México y doce delegaciones políticas. ${ }^{34}$

\subsection{La fase de la reforma legal de la Ley Orgánica del Departamento del Distrito Federal (31 de diciembre de 1970)}

Esta ley amplió las delegaciones políticas de doce a dieciséis 16 las cuales fueron: Gustavo A. Madero, Azcapotzalco, Iztacalco, Coyoacán, Álvaro Obregón, La Magdalena Contreras, Cuajimalpa de Morelos, Tlalpan, Ixtapalapa, Xochimilco, Milpa Alta, Tláhuac, Miguel Hidalgo, Benito Juárez, Cuauhtémoc y Venustiano Carranza. El texto legal volvió reiterar (artículo 9) que "los límites del Distrito Federal son los fijados por los decretos del 16 y 17 de diciembre de 1898 expedidos por el Congreso de la Unión”.

Con ello se ratificaban los convenios sobre los límites territoriales celebrados con los Estados de Morelos y México respectivamente. De esta manera en las 16 fracciones de su artículo 11 se detallaron los límites precisos de cada una de las Delegaciones. Sin embargo, esta Ley contiene una "perla” en el artículo 10 que a la letra dijo: "el Distrito Federal o Ciudad de México se divide para los efectos de esta ley y de acuerdo con sus características geográficas, históricas, demográficas, sociales y económicas en 16 Delegaciones". Atrás quedó la época en que el Distrito Federal era una parte de la Ciudad de México o la Ciudad de México una parte del Distrito Federal. Los dos son

\footnotetext{
33 Texto reglamentario de la base primera de la fracción VI del artículo 73 constitucional.

34 Lo dividió en dos entidades jurídico-políticas distintas: la Ciudad de México y las delegaciones de Villa Gustavo Amadero, Azcapotzalco, Ixtacalco, Coyoacán, Villa Álvaro Obregón, La Magdalena Contreras, Cuajimalpan, Tlalpan, Ixtapalapa, Xochimilco, Milpa Alta y Tláhuac.
} 
una y la misma cosa. Sin embargo, como enseguida se demostrará, con el correr del tiempo ya no son -ni pueden ser- la misma cosa. Aquí se localiza el parteaguas. ${ }^{35}$

\subsection{La fase de la Ley Orgánica del Departamento del Distrito Federal (31 de diciembre de 1972)}

Más allá de lo anterior, esta ley no contiene ninguna otra innovación digna de ser mencionada. Lo único que hizo fue modificar los límites territoriales de las 16 delegaciones políticas creadas por la ley del 31 de diciembre de 1970.

\subsection{La fase de la reforma constitucional del artículo 73 (10 de agosto de 1987)}

El 10 de agosto de 1987 es publicada en el Diario Oficial de la Federación la reforma a la fracción VI del artículo 73 constitucional mediante la cual se redefinen las facultades legislativas del Congreso de la Unión con relación al Distrito Federal. ${ }^{36}$

Lo fundamental de esta reforma consistió en crear una Asamblea de Representantes del Distrito Federal integrada por $\mathbf{4 0}$ miembros electos por votación mayoritaria y 26 de representación proporcional. Se detallaron una serie de facultades y atribuciones concedidas a este nuevo órgano de gobierno que más que nada fue concedido como un órgano de participación vecinal y de deliberación ciudadana, toda vez que las facultades legislativas con respecto al Distrito Federal seguían estando a cargo del Congreso de la Unión y a la Asamblea de Representantes sólo se le concedían facultades para dictar bandos, ordenanzas y reglamentos. Lo rescatable fue que la Asamblea fue concebida como un órgano de deliberación colectiva electa en votación directa de los ciudadanos.

35 En este punto particular vale la pena contextualizar que el hecho de que el presidente de la República presentara sus iniciativas el 31 de diciembre de 1970 marca el inicio de una acentuada práctica política y regla no escrita del régimen revolucionario. Al mes de haber tomado posesión de su cargo, el presidente presentaba las iniciativas legislativas más importantes obligando al Congreso de la Unión a legislar bajo presión y “de rodillas”. Esta práctica legislativa es sin duda la mejor expresión el régimen revolucionario y del presidencialismo priísta. Además de que se partía de la premisa de que cambiando las leyes se modificaba la realidad. Por lo tanto, si por ley se declaraba que el Distrito Federal y la Ciudad de México eran una y la misma cosa, no habría ningún problema para que esto fuera aceptado por la población: el sistema político funcionaba; y, por lo tanto, las disposiciones del presidente de la República avaladas por el Congreso de la Unión fueron acatadas sin mayor reparo por los habitantes de la Ciudad de México y del Distrito Federal en lo que disponía la ley en términos de que esas dos entidades distintas eran una misma realidad.

36 Esta fracción ya había sido modificada el 21 de septiembre de 1944. Por otro lado, en esta reforma no sólo se reiteraron las facultades que el Constituyente de 1917 había otorgado al Congreso de la Unión "para legislar en todo lo relativo al Distrito Federal”, sino que en esta ocasión el legislador ordinario elevó a rango constitucional las facultades del presidente de la República con relación al Distrito Federal, en un artículo que está dedicado a las facultades del Congreso de la Unión. 


\subsection{La fase de la reforma constitucional del artículo 73 fracción VI y al 122 constitucional (25 de octubre de 1993)}

Esta reforma estableció la facultad del Congreso de la Unión para expedir el estatuto del gobierno del Distrito Federal y legislar en lo relativo a él, salvo a las materias expresamente conferidas a la Asamblea de Representantes. Con este reforma se dio la última ocasión en la que el Distrito Federal quedaba incluido en la fracción VI del artículo 73 constitucional. Se produjo así una paradoja en la que el Congreso de la Unión dejó de tener facultades legislativas en el Distrito Federal mediante la derogación de la fracción VI del artículo 73. Sin embargo las atribuciones del Congreso de la Unión fueron trasladadas a una nueva versión de un artículo 122 constitucional con una fracción I en la que se establecen o se reiteran las facultades legislativas del Congreso de la Unión con respecto al Distrito Federal.

Por otro lado, en 1993 se llevó a cabo una de las múltiples reformas que han afectado al régimen jurídico de la capital del país. Esta reforma tuvo como particularidad que gran parte de su contenido quedó frenado en artículos transitorios que impidieron su aplicación efectiva. Una de las innovaciones de la reforma que sí alcanzó a tener efectos prácticos fue la incorporación en el artículo 122 de la Constitución de una figura de participación ciudadana llamada "Concejos Ciudadanos. La función de estas instancias quedó establecida en el propio texto constitucional y estaba dirigida a intervenir en: "la gestión, supervisión, evaluación y, en su caso, consulta o aprobación, de aquellos programas de la administración pública del Distrito Federal que para las demarcaciones determinan las leyes correspondientes". La elección de los consejeros ciudadanos sería directa en cada demarcación territorial y las bases correspondientes quedarían establecidas en el Estatuto de Gobierno del Distrito Federal, que emite y reforma el Congreso de la Unión. Adicionalmente, la Constitución otorgaba a la Asamblea de Representantes la facultad de "legislar en el ámbito local, en lo relativo al Distrito Federal en los términos del Estatuto de Gobierno en materias de participación ciudadana" ${ }^{37}$

Las innovaciones más importantes de esta reforma constitucional a nuestro decir fueron las siguientes:

1. Concedió facultades legislativas acotadas a la Asamblea de Representantes del Distrito Federal;

2. Se estableció la cláusula de gobernabilidad para que el partido político que obtuviera al menos el 30\% de la votación en la elección de representantes ante la Asamblea Legislativa, se le otorgara la mayoría absoluta de miembros ante dicho órgano legislativo;

3. Se cambió el nombre del titular del organismo ejecutivo-administrativo de gobierno del Distrito Federal. Dejó de ser Jefe del Departamento del Distrito Federal para

37 Ugarte Salazar, Pedro (1998): "La situación de la participación ciudadana en el Distrito Federal. Un punto de vista legal”, en Diálogo y Debate de Cultura Política (julio-diciembre), p. 113. 
convertirse en Jefe del Distrito Federal: es decir, el Departamento Central creado mediante decreto de 31 de diciembre de 1941, dejó de existir;

4. Se estableció la elección indirecta del jefe del Distrito Federal. Éste sería nombrado por el presidente de la República "de entre cualquiera de los representantes a la Asamblea, diputados federales o senadores electos en el Distrito Federal, que pertenezcan al partido político que por sí mismo obtenga el mayor número de asientos en la Asamblea de Representantes. El nombramiento sería sometido a la ratificación de dicho órgano, que contará con un plazo de cinco días para, en su caso, ratificarlo. Si el nombramiento no fuese ratificado, el presidente presentará a la Asamblea un segundo nombramiento para su ratificación dentro de un plazo de cinco días. Si no hubiera ratificación del segundo nombramiento, el Senado hará directamente el nombramiento del Jefe del Distrito Federal". Este que ha sido, sin lugar a dudas, el procedimiento más acertado para la elección y designación del titular del órgano de gobierno político-administrativo del Distrito Federal, lamentablemente nunca se practicó debido a que el transitorio Quinto de la reforma constitucional en cuestión establecía que "el primer nombramiento para el cargo de Jefe del Distrito Federal, en los términos de este decreto se verificará en el mes de diciembre de 1997 y el periodo constitucional respectivo concluirá el dos de diciembre del año 2000". Por razones más que nada derivadas de la presión y negociación política, la reforma constitucional del 22 de agosto de 1996 hizo que esta reforma constitucional quedara sobreseída y nunca fuera aplicada.

No obstante, si bien la reforma legal del 31 de diciembre de 1970 estableció la sinonimia entre Ciudad de México y Distrito Federal, esta reforma elevó a rango constitucional esta confusión al modificar el artículo 44 constitucional agregándole una primer frase que es la madre de todas las confusiones: "la Ciudad de México es el Distrito Federal".38

\subsection{La fase de la reforma de 1996}

La innovación más importante de esta reforma fue establecer la elección directa del titular del órgano de gobierno político-administrativo de lo que se denomina Distrito Federal asimilado, desde 1970, como sinónimo de Ciudad de México. Su titular cambió por cuarta ocasión de nombre al de jefe de Gobierno del Distrito Federal. En nuestra particular interpretación el nombre de la autoridad ejecutiva de la Ciudad de México no parece el más adecuado, ya que puede llevar a confusiones con los dignatarios de otros países que se pueden confundir y llegar a suponer que el Ejecutivo de la Ciudad de México por llamarse Jefe de Gobierno correspondería a la figura de un primer ministro en un sistema semipresidencial o parlamentario. En nuestra opinión el nombre correcto debería ser Alcalde de la Ciudad de México. ${ }^{39}$

38 La reforma de esta ocasión consistió en la modificación de artículo 44 constitucional; la derogación de la fracción VI del artículo 73 constitucional; y, la modificación del artículo 122 para incluir ahí todo lo relativo al Distrito Federal que fue creado y lo que anteriormente estaba en el artículo 73 constitucional.

39 Esta figura ha pasado por los siguientes nombres: gobernador (1917 a 1928); Jefe del Departamento Central o Jefe del Departamento del Distrito Federal (1928 a 1941). En este punto cabe señalar que 
No obstante del aparente avance o progreso que implicaba una reforma política para el Distrito Federal, cuyo contenido más importante fue la elección popular y directa del titular de su órgano de gobierno político-administrativo. En este particular, al igual que con lo anterior, el mecanismo de elección de la autoridad ejecutiva de la Ciudad de México si bien implica la devolución de un derecho que durante mucho tiempo no tuvieron los ciudadanos de la capital del país, por otro lado implica generar una fuente continua de disputa por la legitimidad de las dos principales figuras políticas unipersonales que residen en ella: el Presidente de la República y el Jefe de Gobierno. Esto provoca desde descortesías políticas hasta confrontaciones entre estas dos autoridades. En nuestra opinión el mejor mecanismo de elección de la autoridad ejecutiva del Distrito Federal era el contenido en la reforma al artículo 122 constitucional del 25 de octubre de 1993 que no llegó aplicarse:

...a) El Jefe del Distrito Federal [alcalde] será nombrado por el Presidente de la República de entre cualquiera de los representantes a la Asamblea, Diputados Federales o Senadores electos en el Distrito Federal, que pertenezca al partido político que por sí mismo tenga el mayor número de asientos en la Asamblea de Representante. El nombramiento será sometido a la ratificación de dicho órgano, que contará con un plazo de cinco días para, en su caso, ratificarlo. Si el nombramiento no fuese ratificado el Presidente presentará a la Asamblea un segundo nombramiento para su ratificación dentro de un lapso de cinco días. Si no hubiera ratificación del segundo nombramiento el Senado hará directamente del Jefe del Distrito Federal.

No obstante del aparente avance o progreso que implicaba la reforma política, la dualidad jurídico-constitucional siguió prevaleciendo: al presidente de la República le correspondía la facultad de expedir el nombramiento de quien tuviera el mando directo de la fuerza pública del Distrito Federal y proponer al Senado quien deba sustituir al jefe de Gobierno en caso de que éste haya sido removido por el propio Senado de la República. Además, el presidente retiene dos atribuciones importantísimas que regularmente pasan desapercibidas: a él le correspondía someter al Congreso de la Unión, en su caso, los montos de endeudamiento necesarios para el financiamiento del presupuesto de egresos del Distrito Federal; y, además de la facultad de iniciar leyes ante el Congreso de la Unión en lo relativo al Distrito Federal, tiene la facultad reglamentaria de todas las leyes expedidas y que se expidan sobre el Distrito Federal por el Congreso de la Unión.

En el contexto de esta reforma parece hasta cierto punto irrelevante pensar que las reforma política a futuro del Distrito Federal se reduzca a la disputa baladí de que si el presidente de la República debe seguir interviniendo en el nombramiento del titular

debido a falta de técnica legislativa existía confusión y sinonimia entre los conceptos Jefe del Departamento Central y Jefe del Departamento del Distrito Federal. Luego jefe del Departamento del Distrito Federal (1941 a 1993); jefe del Distrito Federal (1993 a 1997) y, ahora (de 1996 a la fecha). 
de la Seguridad Pública del Distrito Federal; de si debe o no ejercer el derecho a proponer quien deba sustituir al Jefe de Gobierno del Distrito Federal en caso de que éste sea removido por el Senado; de si, en ese caso, la aprobación del sustituto debe corresponder al Senado o a la Asamblea Legislativa; y, de si la Asamblea Legislativa es un Órgano Legislativo sui géneris o si le deben de corresponder todas las facultades y atribuciones que tienen las legislaturas de los estados de la República Mexicana.

Consideramos que esto es hasta cierto punto no es concebible; puesto que, a nuestro juicio la verdadera reforma posible de gran alcance que venga a resolver de fondo la naturaleza jurídico-política del Distrito Federal consiste en superar la confusión existente entre la Ciudad de México y el Distrito Federal; redefinir claramente las competencias entre los órganos de gobierno locales y los poderes federales en el territorio de lo que hoy es el Distrito Federal; y, modificar el estatus o denominación misma de esa realidad confusa que hoy se llama Ciudad de México y Distrito Federal, así como imaginar y crear nuevos órganos de gobierno para una realidad que ya no es la misma de 1970 ni de 1996.

\section{EL DEBATE ACTUAL (1997-2009) $)^{40}$}

Desde el 22 de agosto de 1996, fecha en que fue aprobada la última reforma constitucional referida al Distrito Federal, hasta mayo de 2009 se presentaron 43 iniciativas de reformas constitucionales sobre temas diversos que atañen tanto al artículo 122 como al 44 constitucionales en las partes sustantivas del estatuto político o el diseño institucional de la capital del país. ${ }^{41}$

Lo anterior no significa que no haya existido interés por parte de los legisladores de los distintos partidos para mejorar las normas constitucionales referidas al Distrito Federal o bien para adaptarlas a las nuevas realidades. El problema ha sido la ausencia de voluntad política y liderazgo para sacarlas adelante o una comprensión clara y profunda del problema que tiene la capital mexicana en el diseño del Estado mexicano y la conformación de un sistema político que conduce más al conflicto que al acuerdo.

Dado que desde 1997 el partido del presidente de la República no goza de mayoría absoluta en la Cámara de Diputados del Congreso de la Unión (y a partir del año 2000 tampoco en la de Senadores), no es posible entonces adjudicar a una fuerza política el que ninguna de esas iniciativas haya prosperado y se hayan incorporado o reformado al texto constitucional.

40 Las iniciativas revisadas fueron consultadas en la Base de Datos de las Iniciativas Presentadas en el Congreso de la Unión página web: http://gaceta.diputados.gob.mx/SIL/Iniciativas/Base.html

41 De todas las iniciativas que fueron analizadas sólo una ha sido aprobada y publicada en el Diario Oficial de la Federación con fecha del 7 de mayo de 2009. 
Probablemente un factor que ha impedido avanzar en lo anterior sea la extrema politización partidaria que en la vida política nacional ha adquirido todo lo que tenga que ver con el Distrito Federal, por el hecho de que sus dos últimos jefes de gobierno han sido candidatos a la Presidencia de la República por partidos opositores a los que han pertenecido los dos últimos titulares del Ejecutivo Federal. No obstante, un hecho es incuestionable: los ciudadanos del Distrito Federal no tienen por qué pagar por esta desafortunada o afortunada circunstancia.

Para realizar el análisis de las iniciativas presentadas en el Congreso de la Unión, se partió del punto de valorar si éstas implicaban un cambio sustancial en la naturaleza política del Distrito Federal, su diseño constitucional, autoridades u órganos de gobierno. De ahí que pudiera haber más iniciativas pero que no implicaban un cambio nodal. En este sentido, las iniciativas estudiadas fueron 43 agrupadas, como producto de su valoración y estudio, en once puntos según el tema o materia que pretendían modificar o reformar.

Las áreas temáticas y el número de iniciativas presentadas en cada uno de ellas fueron las siguientes: a) cuatro con relación al estatuto político-constitucional de la Ciudad de México y el Distrito Federal; b) seis referentes al nombramiento y remoción de la autoridad ejecutiva del Distrito Federal; c) tres referidas a la integración en la representación política en el Distrito Federal; d) cuatro iniciativas referida a las relaciones entre los órganos de gobierno y los Poderes Federales; e) cuatro con relación a la naturaleza y facultades legislativas de la Asamblea Legislativa del Distrito Federal; f) una referida al sistema de partidos en el Distrito Federal; g) dos referidas a la participación ciudadana o democracia semidirecta en el Distrito Federal; h) diez referidas a la relación y competencias entre los órganos de gobierno del Distrito Federal, o bien su integración; i) ocho referidas al fenómeno metropolitano; j) dos referidas a las competencias del Presidente de la República en materia de seguridad pública; y k) una con relación a la fiscalización del Distrito Federal. Cabe señalar que algunas abordaban más de un rubro, por ejemplo las iniciativas que se presentaron el 14 de noviembre de 2001 y el 5 de agosto de 2002 (véase el anexo). Sin embargo, y específicamente, su contenido, objeto o materia fue el siguiente:

\subsection{Iniciativas con relación al estatuto político-constitucional de la Ciudad de México y el Distrito Federal ${ }^{42}$}

La primera iniciativa que se presentó en este rubro tuvo como objeto eliminar la figura del Distrito Federal y la duplicidad legislativa, instalada desde la reforma constitucional de octubre de 1993. Pretendía que el Distrito Federal adquiriera las caracte-

\footnotetext{
42 Véanse las iniciativas presentada los días 1 de diciembre de 1998 por el PRD en la Cámara de Diputados; 20 de marzo de 2003 por el PRI en la Cámara de Diputados; la del 24 de abril de 2007 por el senador del PRD René Arce Islas; y la del 22 de agosto de 2007 por el PRD por diputado Raymundo Cárdenas Hernández.
} 
rísticas de un estado de la Unión, sin perder la condición constitucional de capital de los Estados Unidos Mexicanos y sede de los poderes federales.

Esta iniciativa fue presentada por 38 diputados federales del PRD (Partido de la Revolución Democrática) y buscó, además de eliminar la figura de Distrito Federal y seguir manteniendo la Ciudad de México como sede de los poderes federales, otorgar a un Congreso Constituyente de un Ilamado estado capital la facultad de fijar la extensión de la Ciudad de México que sería sede de ese estado de nueva creación y además capital de los Estados Unidos Mexicanos.

La segunda iniciativa presentada en esta tesitura en el Congreso de la Unión tuvo como intención cambiar el nombre del Distrito Federal por el de "Estado de Juárez" por considerar que de ese modo se integraría más armónicamente al centro de la República, junto con los estados de Morelos e Hidalgo, para fortalecer la independencia e identidad nacional. La propuesta establece que el Distrito Federal seguirá ocupando el territorio que actualmente tiene y que en el caso de que los Poderes Federales se trasladen a otro lugar, o se constituya en una entidad federativa, se erigirá en el estado de Juárez, con los límites y extensión que le asignen el Congreso General.

Esta iniciativa busca reformar dos artículos constitucionales, en el caso del 122 es sumamente detallista y más bien parece una miniconstitución del Distrito Federal insertada en la Constitución Federal. Destacó el hecho de reivindicar para el Distrito Federal un status de entidad federativa, tanto por las prohibiciones que pretende autoimponerse y que serían similares a las de los estados como las que reivindicó para la Asamblea Legislativa del Distrito Federal el derecho a participar en los procesos de aprobación de reformas y adiciones a la Constitución general de la república. Se hizo en los mismos términos en los que intervienen las legislaturas de los estados.

La iniciativa también contempló lo que debía proceder en caso de que al comenzar un periodo constitucional no se presentase el Jefe de Gobierno electo, o la elección no estuviera hecha o declarada. Propuso también, en los mismos términos que la iniciativa comentada anteriormente, lo que procede en caso de falta absoluta del jefe de Gobierno en los dos primeros años, o en los últimos cuatro de su mandato. Por otro lado, con respecto a los requisitos para ser Jefe de Gobierno del Distrito Federal, modificaba el de residencia, proponiendo pasar de una residencia efectiva de tres años que actualmente puede tener cualquier ciudadano mexicano por nacimiento por una residencia ininterrumpida de tres años para los originarios del Distrito Federal y de cinco para los nacidos en otra entidad.

Por lo que respecta a las facultades y obligaciones del jefe de Gobierno, adicionó diversas disposiciones entre las que destacan la de "presidir el Consejo de Delegados Políticos" y define las delegaciones políticas del Distrito Federal y la forma de elección de sus titulares, lo que parece inadecuado incluir en el texto de una constitución federal. 
La tercera iniciativa con relación al estatuto político-constitucional de la Ciudad de México y el Distrito Federal presentada al pleno de una de las dos Cámaras, propuso la creación del estado de Anáhuac como capital de la República, y abre el camino, para la definición de su organización política, económica y social, en su propia constitución local. Parece contradictorio que se quiera transformar al Distrito Federal en un estado, en este caso llamado de Anáhuac, y que éste no pueda tener una capital propia por ser sede de los poderes federales, por lo que no se puede entender entonces dónde residirían los poderes de ese estado o si ese estado no tendría poderes locales.

La última iniciativa en este rubro formuló sustituir en todo el texto constitucional el término Estados Unidos Mexicanos por el de México. Lo anterior, en virtud de que se considera que el primero de ellos no era una designación de carácter político, sino geográfico, mientras que el segundo comprendía el significado del federalismo y la soberanía de nuestro país.

\subsection{Iniciativas referentes al nombramiento y remoción de la autoridad ejecutiva del Distrito Federal ${ }^{43}$}

La primera iniciativa presentada en este tenor sostuvo que el nombramiento del Jefe del Gobierno del Distrito Federal, en caso de remoción, fuera facultad exclusiva de la Asamblea Legislativa del Distrito Federal. Adicionalmente, propuso suprimir la injustificada injerencia de los órganos federales en encuestas y esferas locales. Esta iniciativa fue presentada a un poco más de un año de aprobada la reforma constitucional del 22 de agosto de 1996. Destaca en todo caso por su carácter radical al plantear la derogación del inciso a) y b) del artículo 122 . Prácticamente planteó la eliminación de las atribuciones de los poderes federales en la capital de la República pese a que éste seguía denominando Distrito Federal y sede de los poderes federales.

La iniciativa establecía también sustituir las atribuciones del senado con respecto del Jefe de Gobierno del Distrito Federal por la Asamblea Legislativa; y que el mando de la fuerza pública en el Distrito Federal, corresponda al Jefe de Gobierno quien podría designar y renovar al senador público que tenga su mando directo.

Por los demás, no deja de llamar la atención curiosamente que está suscrita por quienes en ese entonces eran dos destacados diputados panistas. En ese entonces el PAN era un partido de oposición al gobierno federal como en relación al recién electo gobierno del Distrito Federal. Vale la pena cuestionarse si al término de la primera década del siglo XXI esta iniciativa la suscribiría algún diputado o senador panista.

43 Véanse las iniciativas presentadas los días 12 de noviembre de 1997 por el PAN en la Cámara de Diputados; 14 de noviembre de 2001 por la Asamblea Legislativa del Distrito Federal; la del 14 de diciembre de 2001 por el PRI en la Cámara de Senadores; la del día 5 de agosto de 2002 por los partidos del PRD y PAN, y concretamente por la senadora Cecilia Romero Castillo; la del 22 de agosto de 2005 por el PRI, vía el diputado Hugo Rodríguez Díaz; y la del 14 de octubre de 2006 por el PAN por medio del senador Guillermo Padrés Elías. 
La iniciativa del 14 de noviembre de 2001 representa la segunda propuesta de cambio constitucional. Ésta busca modificar la fracción IX del artículo 76 Constitucional para elevar el quórum de votación exigido para la remoción del Jefe de Gobierno por el Senado de la República a dos terceras partes de los miembros de dicha Cámara; dejar asentado que dicha facultad sólo le corresponde al Senado de la República y no, como indica la previsión vigente, a la Comisión Permanente durante los recesos de aquél; y someter el ejercicio de esta facultad a una legislación reglamentaria que deberá expedir el Congreso de la Unión.

La tercera iniciativa en este orden de ideas está orientada a determinar las causas de remoción del Jefe de Gobierno capitalino. En esta iniciativa se pretende detallar al grado de una ley reglamentaria y cuáles son las causas graves que afectan las relaciones de los poderes de la Unión o el orden público en el Distrito Federal, para que pueda proceder la remoción del Jefe de Gobierno del Distrito Federal por el Senado de la República; o en sus recesos, por la Comisión Permanente.

Si bien es cierto que se requiere detallar esto para que se eviten discrecionalidades y subjetividades en el ejercicio de dicha atribución, también lo es que esto más bien debería establecerse en el Estatuto de Gobierno del propio Distrito Federal y no en la Constitución General de la República.

La iniciativa del 5 de agosto de 2002 es la cuarta que se presentó y busca reformar lo referente al nombramiento y remoción de la autoridad ejecutiva del Distrito Federal busca otorgarle al Congreso de la Unión facultades para establecer los casos y el procedimiento a seguir para la remoción del Jefe de Gobierno del Distrito Federal; y, a diferencia de la anterior iniciativa, no establece dichos casos sino que mandata al Congreso de la Unión para que en una legislación secundaria los plasme.

De igual forma, concede atribuciones al Presidente de la República para instruir de manera fundada y motivada a las autoridades del Distrito Federal para hacer frente a situaciones cuya relevancia requiera acciones urgentes. Propone también una mayoría especial para emitir y reformar el Estatuto Constitucional del Distrito Federal. Ya en un plano más acorde al fortalecimiento de las autoridades locales del Distrito Federal, establece el principio de distribución de competencias de carácter residual que actualmente existe para los estados con respecto de la Federación en el artículo 124 constitucional. Al igual que otras iniciativas presentadas, la presente reivindica el derecho de la Asamblea Legislativa de participar en el proceso de aprobación de adiciones y reformas a la constitución. Finalmente, propone la creación de un Instituto Electoral del Distrito Federal y de un Tribunal Electoral de esa misma entidad.

La quinta iniciativa tiene por objeto adecuar el marco legal de la Constitución para otorgar a la Asamblea Legislativa del Distrito Federal la facultad exclusiva de remover y nombrar a quien deba sustituir, en caso de remoción por falta absoluta, por renuncia o cualquier otra causa, al jefe del Gobierno del Distrito Federal. 
Esta iniciativa es un absurdo. Si se le otorgarán a la Asamblea Legislativa del distrito Federal facultades para remover y nombrar al Jefe de Gobierno del Distrito Federal entonces estaríamos en el caso de un sistema parlamentario de orden local, en donde mediante el voto de censura se pudiera destituir a los titulares de los órganos o poderes ejecutivos. Además, eliminar la intervención del Presidente en la propuesta de quien pueda sustituir al Jefe de Gobierno, en caso de que este sea removido por el Senado de la República, no parece adecuado por ser el Distrito Federal la sede de los Poderes Federales. En todo caso, lo que sí podría hacerse es que sólo en casos de remoción por el Senado el Presidente de la República propusiera ya no al propio Senado de la República, sino a la Asamblea Legislativa del Distrito Federal quien deba sustituir al Jefe de Gobierno.

La sexta iniciativa referente al nombramiento y remoción de la autoridad ejecutiva del Distrito Federal, tiene como objeto instaurar la segunda vuelta electoral para la elección de Presidente de la República, de gobernadores de los estados y del Jefe de Gobierno del Distrito Federal. Plantea la realización de una segunda vuelta electoral cuando ningún candidato obtenga más del 45 por ciento de la votación válida emitida, o cuando aconteciendo este supuesto, la diferencia ente el primero y segundo lugar sea menor a 5 puntos porcentuales respecto del total de la votación válida.

Esta iniciativa parece innecesaria, ya que si lo que se quiere es asegurar la debida gobernabilidad en el Distrito Federal, eso no se logra con la segunda vuelta electoral en la elección de su Jefe de Gobierno, sino que eso se consigue a través del hecho de que el partido de este gobernante tenga mayoría absoluta en la Asamblea Legislativa, y esto ya está garantizado en virtud de la fracción III de la Base Primera del artículo 122 constitucional.

\subsection{Iniciativas referidas a la integración de la representación política en el Distrito Federal ${ }^{44}$}

La primer iniciativa de este rubro propone eliminar en el texto del artículo 122 constitucional, el procedimiento de sobre representación (cláusula de gobernabilidad) para sustituirla por la asignación de diputados de representación proporcional a través de un sistema de proporcionalidad pura, en virtud de la cual los 26 diputados de representación proporcional sean asignados conforme al porcentaje de votación obtenido por cada partido para que haya una relación directa entre los diputados de representación proporcional asignados y los votos obtenidos por los partidos.

Podrá parecer cuestionable otorgar mayoría absoluta en un órgano legislativo a un partido político que siendo el más votado sólo haya obtenido el 30\% de la votación;

\footnotetext{
44 Véanse las iniciativas presentadas los días 24 de agosto de 2002 por el PT y concretamente por el diputado Víctor Antonio García Dávila; la del 22 de noviembre de 2005 por el PRI, concretamente por el senador Silvia Hernández Enríquez; y la del 8 de noviembre de 2007 por la diputada Elsa de Guadalupe Conde Rodríguez.
} 
sin embargo, en el caso del Distrito Federal, esto pudiera resultar entendible toda vez que un escenario en el que la Asamblea Legislativa estuviera dominada por un partido político, otro diferente tuviera la jefatura de gobierno, y el Presidente de la República fuera miembro de una formación política distinta a las dos anteriores se correría el riesgo de la ausencia de coordinación y la falta de gobernabilidad, lo que podría generar un problema serio para el debido funcionamiento tanto de los poderes federales, como del órgano ejecutivo-administrativo del Distrito Federal. Por lo anterior, la iniciativa propuesta no parece sustentada ni viable.

La segunda iniciativa en este tenor tiene por objeto establecer la reelección inmediata de legisladores y munícipes. Si bien es cierto que la restricción para la reelección consecutiva de los legisladores locales sólo atañe a los diputados que integran las legislaturas de los estados (tal y como lo establece el artículo 116 constitucional) y como el Distrito Federal no es estado, entonces esa restricción no aplica para sus legisladores locales. Sin embargo, parece una contradicción que por un lado se subrayen los rasgos atípicos del régimen jurídico-político del Distrito Federal tan sólo por reivindicar una demanda que puede parecer muy justa, pero que sin embargo va en sentido inverso a la demanda mayor de dotar al Distrito Federal de un régimen jurídico-político similar al de los estados.

La tercera iniciativa en esta tesitura busca regular en el ámbito constitucional la equidad de género e igualdad de oportunidades en materia electoral: obliga a los partidos políticos a presentar en igual proporción de género (50-50) sus listas de candidatos a cargos de representación popular. ${ }^{45}$

\subsection{Iniciativas referidas a las relaciones entre los órganos de gobierno y los Poderes Federales ${ }^{46}$}

La primera iniciativa de esta clasificación propone que el Distrito Federal participe en la misma proporción que las demás entidades federativas en el gasto destinado a la educación básica. Una segunda pretende instituir la figura de cabildo en el caso del gobierno del Distrito Federal. En tanto que la tercera iniciativa propone incorporar a la Asamblea Legislativa del Distrito Federal entre los sujetos facultados para presentar iniciativas ante las Cámaras del Congreso, y para que se integre al Constituyente Permanente y pueda participar en el proceso de aprobación de reformas constitucionales.

Finalmente la cuarta en este rubro pretende dotar al Distrito Federal de todas las prerrogativas de una entidad federativa. En particular propone: 1) dotar a la Asamblea

45 Para ello modifica los artículos 35, 41, 116 y 122 de la Constitución y 8, 11, 38, 42, 56, 175 y 175-A del Código Federal de Instituciones y Procedimientos Electorales.

46 Véanse las iniciativas presentadas los días 14 de noviembre de 2001 por la Asamblea Legislativa del Distrito Federal; la del 5 de agosto de 2002 por los partidos del PRD y PAN, y concretamente por la senadora Cecilia Romero Castillo; la del 11 de diciembre de 2003 por el PRI; el 25 de enero de 2006 por el PRD, y suscrita por el diputado Iván García Solís; la del 8 de noviembre de 2007 por el diputado Odulio Ávila Mayo del PAN; y la del 28 de febrero de 2008 por la diputada Silvia Oliva Fragoso del PRD. 
Legislativa del Distrito Federal de facultades para fijar los montos de endeudamiento de la ciudad, 2) permitirle participar en el proceso de aprobación de las reformas constitucionales, 3) suprimir la facultad del Senado de remover al jefe de gobierno de la ciudad, 4) eliminar el requisito de votación del 33\% de los diputados locales para que la Asamblea Legislativa pueda promover una acción de inconstitucionalidad, y 5) otorgar nuevas facultades a las demarcaciones políticas del Distrito Federal.

\subsection{Iniciativas con relación a la naturaleza y facultades legislativas de la Asamblea Legislativa del Distrito Federal ${ }^{47}$}

La única iniciativa que se presentó en este rubro tiene como objeto que la Asamblea Legislativa del Distrito Federal participe como Legislatura local en los procesos de reformas constitucionales y pueda presentar iniciativas de Ley igual que los Congresos Locales. Busca otorgarle al Distrito Federal facultades similares al resto de las entidades federativas, dada la importancia político-electoral de la sede de los poderes de la Unión.

Esta iniciativa, presentada por la Asamblea Legislativa del Distrito Federal en ejercicio de las atribuciones que el confiere el inciso ñ) fracción $V$ de la base primera del artículo 122 constitucional. También pretende otorgar amplios poderes al órgano legislativo del Distrito Federal tanto para expedir leyes en todo lo relativo al Distrito Federal como para intervenir en la designación del Jefe de Gobierno en caso de renuncia absoluta designando un Jefe de Gobierno interino si la falta ocurriere en los dos primeros años y de un Jefe de Gobierno sustituto si esta se presentare dentro de los últimos cuatro años del período respectivo. Así mismo que el Procurador General de Justicia sea nombrado por el Jefe de Gobierno del Distrito Federal con la ratificación de las dos terceras partes de los integrantes de su Asamblea Legislativa y aprobar los montos del endeudamiento que requiera el gobierno del Distrito Federal.

\subsection{Iniciativas referidas al sistema de partidos en el Distrito Federal ${ }^{48}$}

La única iniciativa presentada en este rubro propone que los partidos políticos con representación en el Distrito Federal, puedan competir en los procesos electorales de la Ciudad sin que sea necesario que cuenten con el registro de partido político nacional. Asimismo, establece la obligación de los gobiernos estatales para asignar recursos económicos a los partidos políticos locales.

Esta iniciativa parece adecuada ya que si en el Distrito Federal se eligen autoridades locales, no obstante de que este sea sede de los poderes federales, hecho que por sí sólo no puede impedir que para el caso de la elección de este tipo de autoridades

\footnotetext{
47 Véase la iniciativa presentada el 20 de abril de 1999 por el diputado panista José Espina Von Roerich.

48 Véanse las iniciativas presentadas los días 12 de diciembre de 2000 por el PRI en la Cámara de Diputados, y la del 15 de abril de 2004 por el PRI presentada por el senador David Jiménez González.
} 
puedan participar partidos políticos locales que hayan obtenido su registro conforme a la ley; máxime cuando en el Distrito Federal se cuenta con un Instituto Electoral.

\subsection{Iniciativas referidas a la participación ciudadana o democracia semidirecta en el Distrito Federal ${ }^{49}$}

La primera iniciativa presentada en esta clasificación pretende establecer un régimen democrático representativo y participativo en la que se dé viabilidad jurídica al referéndum, el plebiscito y la iniciativa popular, y

La segunda propone instituir la figura de revocación del mandato para servidores públicos de elección popular. Correspondiendo al IFE, comprobar los requisitos exigidos en la ley, y convocar a procedimiento electoral para llevarlo a cabo dentro de los noventa días de presentada la petición. El procedimiento tendrá efecto vinculante si los votos favorables a la revocación son mayoritarios y hubiese sufragado más del $50 \%$ de los electores del padrón que corresponda.

\subsection{Iniciativas referidas a la relación y competencias entre los órganos de gobierno del Distrito Federal, o bien su integración ${ }^{50}$}

La primera iniciativa (del 14 de noviembre de 2001) plantea autonomía para el gobierno local y la definición de competencias específicas para el gobierno federal. Modifica la fracción VIII del artículo 73 Constitucional, a fin de suprimir la parte conducente del texto en relación con la facultad del Congreso de la Unión para aprobar anualmente los montos de endeudamiento que requiera el Gobierno del Distrito Federal y la obligación del Presidente de la República para rendir al propio Congreso los informes correspondientes al ejercicio de dicha deuda.

La segunda que se presenta en este sentido es la del día 5 de agosto de 2002, la cual busca reformar las relaciones entre los órganos de gobierno y los poderes federales. La iniciativa retoma las propuestas fundamentales contenidas en la Minuta que el Senado recibió de la Cámara de Diputados, el 15 de diciembre de 2001, mediante la cual se pretende el fortalecimiento de las instituciones del gobierno del Distrito Federal a través de propuestas relativas a su autonomía jurídica y política.

49 Véanse las iniciativas presentadas los días 7 de agosto de 2000 por el PAN en la Cámara de Diputados, y la del 11 de diciembre de 2008 por la diputada Lorena Martínez Rodríguez del PRI.

50 Véanse las iniciativas presentadas el día 24 de abril de 2003 por el PAN, mediante el senador Adalberto Madero Quiroga; la del 14 de mayo de 2003 por la Asamblea Legislativa del Distrito Federal y turnada a la Comisión Permanente; la del 27 de abril de 2004 presentada por el PAN; el 28 de abril de 2005 por el PVEM y concretamente por el diputado Jorge Antonio Kahwagi Macari; la del 11 de enero de 2006 por el PRD, suscrita por el diputado Iván García Solís y turnada a la Comisión Permanente y ésta a su vez a la Cámara de Diputados; la del 25 de enero de 2006 por el PAN por medio del senador Carlos Manuel; la del 28 de marzo de 2006 por el PAN en la Cámara de Senadores; el 4 de octubre de 2007 por el PAN mediante el diputado Martín Lujano Nicolás; así como la del día 2 de abril de 2009 por la Comisión de Puntos Constitucionales de la Cámara de Diputados. 
Entre esta iniciativa presentada por una senadora panista, "a nombre de un senador perredista” (que después fue converso al panismo) y la que presentaran diputados del PAN el 12 de noviembre de 1997, existe un cambio radical. En principio comprende lo que podría denominarse como cláusula de excepción que aseguren el ejercicio de las funciones de los poderes de la Unión en el Distrito Federal; le otorga al Congreso de la Unión facultades para legislar sobre las facultades implícitas que ahí mismo se le están dando al Presidente respecto del mando de la fuerza pública en el Distrito Federal y de las "relaciones de subordinación del Jefe de Gobierno del Distrito Federal y del servidor público que tenga a su cargo el mando directo de dicha fuerza", con respecto al Presidente.

Una tercera iniciativa propone que se fije un término de 20 días hábiles -posteriores al plazo para realizar observaciones-, para que el Jefe de Gobierno promulgue y publique las leyes que aprueba la Asamblea Legislativa, y que en caso de inobservancia de la norma anterior se establezca el principio de afirmativa ficta.

La cuarta iniciativa presentada en este rubro intenta modificar la fecha establecida en la Constitución y en el Estatuto de Gobierno del Distrito Federal, para que el jefe de gobierno capitalino presente a la Asamblea Legislativa la Ley de Ingresos y el Presupuesto de Egresos de la ciudad, a más tardar el 20 de septiembre de cada año, con excepción del año de la toma de posesión, cuando la fecha se aplaza hasta el 20 de diciembre.

La iniciativa propuesta es congruente y acorde a los plazos establecidos para el mismo objeto para el Presidente de la República en la fracción IV del artículo 74; donde, mediante reforma del 28 de julio de 2004, se adelantó la fecha de presentación de la iniciativa de Ley de Ingresos y el Proyecto de Presupuesto de Egresos de la Federación del 15 de noviembre al 8 de septiembre. Por lo tanto, la redacción actual de este párrafo del artículo 122 es incongruente con la anterior modificación; ya que plantea como fecha límite para la presentación de dichas iniciativas por el jefe de Gobierno del Distrito Federal el 30 de noviembre, siendo adecuado modificar el plazo al 20 de septiembre, como lo propone esta iniciativa.

La quinta iniciativa actualiza el texto constitucional con objeto de ampliar las facultades de la Asamblea Legislativa del Distrito Federal para presentar las iniciativas de ley o decretos ante el Congreso de la Unión, sobre cualquier tema y no solamente las relativas al Distrito Federal. Esta iniciativa puede parecer pertinente. Sin embargo, para que el Distrito Federal pueda tener facultad de presentar ante el Congreso de la Unión iniciativas sobre cualquier tema y no solamente con relación al Distrito Federal, antes debería definirse la situación jurídico-política del Distrito Federal. Mientras esto no proceda no es viable lo propuesto en la iniciativa.

La sexta iniciativa propone dotar a las delegaciones políticas del Distrito Federal, del estatus de cuasi ayuntamientos, con el objeto de que ejerzan en forma concurrente las acciones ejecutivas y brinden los servicios básicos tal como si fuera un ayuntamiento, por otra parte pretende que el electorado esté representado en un consejo de 
representantes a fin de crear un espacio de discusión entre las distintas fuerzas políticas al interior del órgano político administrativo.

La séptima iniciativa referida a la relación y competencias entre los órganos de gobierno del Distrito Federal, o bien su integración tiene como objetivo conferir expresamente a la Asamblea Legislativa del Distrito Federal la facultad de legislar en materia de responsabilidades de los servidores públicos del Distrito Federal.

La octava iniciativa propone otorgar a los órganos político-administrativos o delegaciones del Distrito Federal personalidad jurídica y patrimonio propio, así como dotarlos de autonomía orgánica y funcional.

La novena iniciativa referida a la relación y competencias entre los órganos de gobierno del Distrito Federal, o bien su integración propone la creación del órgano colegiado denominado cabildo delegacional, como órgano de control político. Para que cada Delegación se integré con un titular, al que se le denominará genéricamente jefe delegacional; 12 concejales delegacionales, electos por el principio de representación proporcional en los términos que la ley electoral local establezca, así como también los funcionarios y demás servidores públicos que determinen la ley orgánica y el reglamento respectivos. El jefe delegacional y los concejales delegacionales serán electos en forma universal, libre, secreta y directa cada tres años según lo determine la ley. Por cada concejal delegacional se elegirá un suplente.

La última iniciativa que se presentó en el Congreso de la Unión tiene como objeto organizar y conformar el Consejo de la Judicatura del Distrito Federal.

\subsection{Iniciativas referidas al fenómeno metropolitano ${ }^{51}$}

La primera iniciativa en esta lógica clasificatoria establece la figura de zonas metropolitanas dentro de los límites territoriales de dos o más estados o de un mismo estado. Plantea que en cada zona se constituya un Parlamento Metropolitano, formado por integrantes de los poderes legislativos de las entidades involucradas. Los parlamentos tendrán funciones legislativas y de regulación y control, exclusivamente sobre el territorio urbano y rural de los municipios de la zona metropolitana. Asimismo establece la creación de consejos metropolitanos, los cuales desempeñarán funciones de carácter ejecutivo.

51 Véanse las iniciativas presentadas los días 28 de agosto de 2005 por el senador Demetrio Javier Sodi de la Tijera; la del 6 de diciembre de 2005 por el PRD, vía el diputado Horacio Martínez Meza; la del 18 de enero de 2006 por el PRD por el diputado Iván García Solís; la del 31 de mayo de 2006 por el PRI vía el diputado José Rangel Espinosa; la del día 14 de junio de 2006 por el Congreso del Estado de México y turnada a la Comisión Permanente, y ésta a su vez a la Cámara de Diputados; la del 14 de septiembre de 2006 por el PRI, vía el diputado Óscar Gustavo Cárdenas Monroy; la del 19 de septiembre de 2006 presentada por el PAN por medio del diputado Luis Gustavo Parra Noriega; así como la del día 12 de diciembre de 2007 por el diputado perredista: Jaime Espejel Lazcano. 
La segunda iniciativa propone que el Estado mexicano reconozca en la Constitución: 1) la existencia de las áreas o zonas metropolitanas; 2) la creación del Instituto Nacional para la Planeación Metropolitana; y 3) el establecimiento de normas que garanticen la constitución de las Juntas de Coordinación Metropolitana como entes encargados de la coordinación intermunicipal e interestatal de las metrópolis. Las Juntas se conformarían por gobernadores, presidentes municipales de la zona metropolitana en cuestión y para el caso del Distrito Federal por los jefes delegacionales.

La tercera iniciativa referida tiene como objeto instituir la Legislatura Metropolitana. Para ello propone que las legislaturas de los estados que formen una continuidad demográfica, nombrarán, entre los diputados ya electos, un representante a la Legislatura Metropolitana por cada 350 mil habitantes. Tendrá una duración de tres años y estará facultada para aprobar o en su caso modificar de manera autónoma los presupuestos objeto de los convenios de coordinación que propongan los Ejecutivos estatales y municipales, en los términos de la fracción VI del artículo 115 de la Constitución Política.

La cuarta iniciativa presentada tiene por objeto generar una eficaz coordinación de los municipios conurbanos entre sí, con los estados como rectores del desarrollo de la entidad y con la Federación, en la planeación y ejecución de proyectos, obras y acciones de impacto en sus respectivos territorios.

La quinta iniciativa faculta a los municipios para crear organismos o adoptar las figuras jurídicas que sean necesarias a fin de mejorar los servicios que prestan. También, y con la aprobación las legislaturas locales, podrán celebrar convenios con ayuntamientos vecinos y construir fondos financieros comunes para el desarrollo conjunto de los centros urbanos colindantes.

La sexta iniciativa referida al fenómeno metropolitano busca que la Federación, los estados, el Distrito Federal y los municipios, participen de manera obligada y canalicen recursos públicos de forma oportuna y eficiente para la solución de los requerimientos de las conurbaciones demográficas del país.

La séptima busca reordenar institucionalmente las relaciones de coordinación en las zonas metropolitanas del país; al respecto propone facultar a los tres órdenes de gobierno: federal, estatal, municipal y el Distrito Federal, para realizar convenios de coordinación, asociación y cooperación metropolitana en materia de planeación y prestación de servicios públicos.

La octava propone facultar al Congreso de la Unión para legislar en materia de desarrollo metropolitano y adecuar el marco jurídico a fin de normar la coordinación entre los municipios que conformen un área metropolitana. 


\subsection{Iniciativas referidas a las competencias del Presidente de la República en materia de seguridad pública $^{52}$}

La primera iniciativa referida a este rubro pretende ampliar los ámbitos de competencia de los órganos de gobierno del Distrito Federal, con el propósito de hacer más eficientes las políticas de prevención y combate al delito. Para ello, plantea reformar el texto constitucional, con objeto de facultar a la Asamblea Legislativa capitalina para legislar en lo relativo a la seguridad pública en el Distrito Federal. Estas materias que pretende la iniciativa en cuestión incorporar como atribuciones de la Asamblea Legislativa, por su nivel de especificidad son temas que en rigor deberían de ir en un Estatuto de Gobierno, pero no en una constitución federal.

En tanto que la segunda iniciativa, y última, se refiere a las competencias del Presidente de la República en materia de seguridad pública tiene por objeto otorgar mayores facultades a las autoridades locales en aspectos sustantivos como la seguridad pública y la procuración de justicia. Para ello propone que, junto a la responsabilidad de brindar a los habitantes de la Ciudad de México un clima de seguridad pública y una eficaz procuración de justicia, se otorguen plenas facultades para determinar las políticas públicas y las decisiones sustantivas en la materia que propicien un federalismo moderno entre ámbitos de gobierno, federal y local.

\subsection{Iniciativas con relación a la fiscalización del Distrito Federal ${ }^{53}$}

La única iniciativa en este rubro pretende mejorar la fiscalización de los recursos que ejerce el gobierno del Distrito Federal, para evitar la prescripción de las responsabilidades de los servidores públicos de la capital y garantizar el correcto ejercicio de las finanzas públicas. Parece exagerado que para proceder a crear una entidad superior de fiscalización en el Distrito Federal se tenga que hacer mediante previa aprobación del Congreso de la Unión para reformar la Constitución Federal, cuando esas disposiciones deben de ir en el Estatuto de gobierno del Distrito Federal.

\section{COMENTARIOS FINALES}

Posiblemente el origen de toda la confusión e imprecisión que caracteriza al régimen jurídico-político de la Ciudad de México y del Distrito Federal se localiza en artículo 44

52 Véase las iniciativas presentadas el día 18 de marzo de 2004 por el PAN por medio del diputado Patricia Garduño Morales, y la del 4 de noviembre de 2008 de la diputada del PRD, Josefina Salinas Pérez.

53 Véanse las iniciativas presentadas los días 27 de abril de 2004 presentada por el PRI, y concretamente por los legisladores Georgina Trujillo Zentella, Manuel Bartlett Díaz, Carlos Chaurand Arzate, Laura Alicia Garza Galindo, Mariano González Zarur, Fernando Gómez Esparza, Carlos Rojas Gutiérrez, Dulce María Sauri Riancho, y Enrique Jackson Ramírez; así como la del 19 de enero de 2005 presentada por la Asamblea Legislativa del Distrito Federal y turnada a la Comisión Permanente. Esta a su vez la turnó a la Cámara de Diputados. 
constitucional, que en virtud de la reforma del 25 de octubre de 1993 en su parte conducente reza de la siguiente manera: "la Ciudad de México es el Distrito Federal, sede de los Poderes de la Unión y capital de los Estados Unidos Mexicanos”. No se requiere mucho esfuerzo para darse cuenta que esta definición no corresponde con la realidad.

La definición constitucional, además, es una contradicción en sus propios términos puesto de estar asimilando como iguales dos entes que en su denominación misma son distintos, en la realidad son totalmente diferentes: el Distrito Federal es un concepto jurídico que tiene que ver con una división político administrativa, en tanto que la Ciudad de México es una realidad sociológica y un fenómeno urbano que trasciende totalmente las fronteras de la división geográfica. ${ }^{54}$

En un principio el Distrito Federal era parte de la Ciudad de México (el Distrito Federal de dos leguas de 1824); todavía durante el siglo XIX ambas realidades se asimilaban simbióticamente (todavía durante esta época sí se podía decir que la Ciudad de México era el Distrito Federal). Sin embargo, ya desde 1917 la Ciudad de México pasó a ser una parte de un Distrito Federal conformado a partir de continuas desmembraciones que se le fueron haciendo al entonces Estado de México. Hoy en día la definición del artículo 44 constitucional es una "camisa de fuerza" y es un obstáculo al pleno desarrollo, a la gestión gubernamental y al pleno ejercicio de las atribuciones que les deberían corresponder a las autoridades electas. Como el Distrito Federal o la Ciudad de México es una realidad que desborda no sólo como fenómeno urbano sino por su potencial económico, fiscal y por su importancia política, entonces a los sucesivos gobiernos federales de distinto signo partidario que han existido les ha convenido mantener indefinidamente esa confusión e imprecisión.

De alguna manera esta tautología jurídica han creado mitos de los que se han beneficiado, tanto los poderes federales como las autoridades electas del Distrito Federal. Estos mitos están sustentados en aparentes problemas irresolubles que implica pensar de manera distinta el sistema federal mexicano. Como por ejemplo: que "en un sistema de organización política federal ningún territorio puede ser capital del país y sede de los poderes federales sin que no sea un Distrito Federal". O que "un estado, es decir un

54 En esta confusión caen muchos de los trabajos como los de Serrano Salazar, Oziel (2001): La reforma política del Distrito Federal (Ciudad de México, editado por el Centro de Asesoría Metropolitana SCPlaza y Valdez); y Contreras Bustamante, Raúl (2001): La Ciudad de México como Distrito Federal y entidad federativa. Historia y perspectiva, (Ciudad de México, Porrúa editores), luego entonces en ellos, así como en los actores políticos y miembros del campo jurídico mexicano no hay claridad en el rumbo hacia la solución más adecuada e idónea. Aunque algunos trabajos como los de GonzÁlez OroPEZA, Manuel (2002): “La condición jurídica de la sede de los poderes federales en México", en José María Serna de la Garza (coord.), Federalismo y regionalismos. Memoria del VII Congreso Iberoamericano de Derecho Constitucional (Ciudad de México, editado por Asociación Argentina de Derecho Constitucional-Universidad Complutense de Madrid-Fundación de Derecho Público de Venezuela-Fundación Jurídica Editorial de Venezuela-Hispamer-Pemex-Universidad Central de Chile-Universidad Externado de Colombia-Universidad de Lima-UNAM): pp. 183-196; el de MARVÁn LABORDE, op. cit.; y ABAL Medina, Juan Manuel (2003): "Evaluando las instituciones políticas de los distritos federales", en Perfiles Latinoamericanos, (Núm. 22, pp. 185-213), anuncian las peculiaridades, características y posibles soluciones de los problemas político-constitucionales que tiene la capital mexicana. 
territorio subnacional o miembro del pacto federal, no puede ser sede de los poderes federales y una capital de un estado no puede ser al mismo tiempo capital de los poderes federales”. La política y el derecho comparado se han encargado de señalar que no es así.

Las posibles salidas al atolladero para el caso mexicano consisten en:

Primera: delimitar -como ya se hizo en 1824- dentro de la Ciudad de México un área específica para el Distrito Federal. Es una salida viable si se tuviera que buscar un área despoblada dentro de lo que es la Ciudad de México para construir ahí un Distrito Federal. Empero el costo económico de trasladar la capital la harían inviable. Otra posibilidad de concretar esta alternativa sería volver al Distrito Federal de las dos leguas y al espíritu eminentemente de una federación territorializada como la pensó el Constituyente de 1824 . Y a partir de este espacio establecer un radio de 20 kilómetros para concentrar los poderes federales y sus dependencias. Esta alternativa es prácticamente imposible porque muy seguramente no alcanzaría para albergar todas las dependencias federales y sus empleados, además de que haría sumamente complejo el tránsito de los habitantes por esa área.

El disfrute de los edificios y monumentos históricos que ahí se localizan por nacionales y extranjeros sería imposible. Además en una circunstancia como esta los poderes federales serían constreñidos y desvalorados al estar recluidos en un distrito específico. Otra dificultad adicional sería que se tendría que sacar a la población civil de este territorio o quienes estuvieran en este espacio a condenarlos a vivir sin el pleno ejercicio de sus derechos políticos. Evidentemente esta posibilidad además de inviable es anacrónica.

Segunda: insertar de manera caótica dentro de una ciudad, los poderes federales y sus dependencias en un proceso en el cual inevitablemente en forma paulatina el Distrito se vaya comiendo a la ciudad y quitándole territorio a los estados circunvecinos.

Es una propuesta viable, pues de alguna manera fue lo que ocurrió con el Distrito Federal y la Ciudad de México pero con un alto costo. Este modelo puede ser funcional durante cierto periodo pero llega un momento en que se agota. Cancela la viabilidad futura de una realidad socio-urbana compleja que tarde que temprano genera problemas para la convivencia de autoridades de dos órdenes de gobierno distintas que conviven en un territorio inmerso en contradicciones y vacíos jurídico-constitucionales.

Las relaciones entre órdenes de gobierno inevitablemente se reproducen en una lógica ya sea de la confrontación o la subordinación. Este es el juego en el que estamos inmersos, estamos siguiendo y no queremos cambiar porque la continuidad del modelo genera ganancias para todos los actores políticos, pero menos para la viabilidad de la ciudad y el cabal ejercicio de las atribuciones de sus autoridades legítimamente constituidas.

Tercera: sacar al Distrito Federal de la Ciudad de México y construir un sitio para la residencia de los Poderes federales en un lugar que no sea dentro de una ciudad (el modelo brasileño y en su momento el estadounidense). 
Esta salida es materialmente imposible, dado el alto costo que significaría eso, la dificultad para el traslado de todos los empleados de las dependencias federales y por los problemas que entrañaría localizar un territorio amplio, suficiente, accesible y con los recursos naturales y de infraestructura necesarios.

En el hipotético caso de una situación tal, el artículo 44 constitucional entraría vigor, retomando el espíritu del artículo 46 de la Constitución de 1857 el cual señalaba que "en el caso de que los poderes federales se trasladen a otro lugar (la Ciudad de México), se erigirá en el Estado del Valle de México con los límites y extensión que le asigne el Congreso General”. Esto además de ser un atavismo totalmente inviable en la actualidad es una auténtica incitación a provocar un problema mayúsculo y conflicto y disputa territorial que nunca desde su historia hubiera vivido el Estado mexicano.

Resulta ingenuo suponer que el Estado de México iba aceptar sumisamente que la parte de su territorio que le fue desmembrada para crear el Distrito Federal no la reclamara y que el nuevo estado se llamara del Valle de México siendo fronterizo con el Estado de México. Además, ningún estado de la federación mexicana querrían albergar al Distrito Federal aceptando que se le desmembraran parte de su territorio como tampoco ninguna otra entidad federativa iba a estar de acuerdo con que todo lo que implica el Distrito Federal de la noche a la mañana se transformara en estado con los evidentes desequilibrios que ello provocaría: conflictos recaudatorios y presupuestarios. Esos efectos serían directos e indirectos para todos los estados de la federación mexicana (naturalmente esta alternativa es la que desean los actores políticos favorables a la cultura de la confrontación, la que provocaría enormes conflictos que desestabilizarían totalmente a la nación mexicana).

Cuarta: convertir al Distrito Federal en un estado con municipios en el que uno de ellos, en este caso la Ciudad de México fuera la sede de los poderes federales (sí por la Ciudad de México nos referimos a las delegaciones centrales). La viabilidad es mínima, porque supone prácticamente lo mismo que la alternativa anterior con la diferencia de que no saldrían de su territorio los poderes federales, y con el agravante de que creando al interior de este nuevo estado el régimen municipal previsto en el artículo 115 constitucional se podría generar un problema grave de ingobernabilidad en la capital federal. Por lo demás si el Distrito Federal fuera estado estaría sujeto a todas las obligaciones y a todos los derechos que contempla el 116 constitucional para los demás estados del país (esta idea es la más recurrente, la más fácil de pronunciar y la que mayor impacto comunicacional genera).

En esta idea peregrina ha habido legisladores que han propuesto crear el Estado 32. Para que una alternativa de organización política sea viable el problema fundamental debe resolverse en serio la distribución de competencias.

La política y el derecho comparado nos dicen que se debe erigir a la Ciudad de México en una ciudad-estado. Lo anterior implicaría una reforma de gran calado pero de no existir condiciones para que fuera realizada, mínimamente lo que se sugiere es 
cambiar el nombre de la autoridad ejecutiva por Alcalde de la Ciudad de México; y b) que su forma de elección y/o designación volviera al mecanismo previsto en la reforma constitucional 25 de octubre de 1993, que desafortunadamente nunca fue aplicada.

\section{BIBLIOGRAFÍA}

Abal Medina, Juan Manuel (2003). "Evaluando las instituciones políticas de los distritos federales”, en Perfiles Latinoamericanos, (Núm. 22, pp. 185-213).

Aguilar Villanueva, Luis F. (1991). "Estudio introductorio" en Problemas públicos y agenda de gobierno (Ciudad de México, Miguel Ángel Porrúa editores), pp. 15-72.

Contreras Bustamante, Raúl (2001). La Ciudad de México como Distrito Federal y entidad federativa. Historia y perspectiva (Ciudad de México, Porrúa editores).

Dublán, Manuel y Lozano, José María (2004). La Legislación Mexicana. (Ciudad de México, editada por la SCJN-Tribunal Superior del Estado de México-El Colegio de México-Escuela Libre de Derecho): ts.: 1, 2 y 3.

GonzÁlez Oropeza, Manuel (2002). "La condición jurídica de la sede de los poderes federales en México", en José María Serna de la Garza (coord.), Federalismo y regionalismos. Memoria del VII Congreso Iberoamericano de Derecho Constitucional (Ciudad de México, editado por Asociación Argentina de Derecho Constitucional-Universidad Complutense de Madrid-Fundación de Derecho Público de Venezuela-Fundación Jurídica Editorial de Venezuela-HISPAMER-PEMEX-Universidad Central de Chile-Universidad Externado de Colombia-Universidad de Lima-UNAM), pp. 183-196.

Gortarı, Hiridia de y Regina Hernández Franyuti (1998). La Ciudad de México y el Distrito Federal. Una historia compartida (Ciudad de México editado por el Departamento del Distrito Federal-Instituto Mora).

León-Portilla, Miguel (2003). La construcción de significado en la Historia (Zapopan, editado por El Colegio de Jalisco).

MARVÁn LABORDE, Ignacio (2001). "La cuestión del gobierno representativo en el Distrito Federal”, en Cuestiones Constitucionales, (Núm. 4, enero-junio), pp. 49-83.

Mccowan, Gerard Louis (2005). El Distrito Federal de dos leguas, o como el estado de México perdió su capital (Zinacantepec, editado por El Colegio Mexiquense).

Moreno, María de los Ángeles (2008). ¿Un alcalde para la ciudad de México?”, en Examen, (Año XIX, Núm. 163, septiembre), pp. 48-49.

Serrano Salazar, Oziel (2001). La reforma política del Distrito Federal (Ciudad de México, editado por el Centro de Asesoría Metropolitana SC-Plaza y Valdez).

Tena Rámirez, Felipe (1997). Derecho constitucional mexicano (Ciudad de México, Porrúa editores).

UGarte Salazar, Pedro (1998): "La situación de la participación ciudadana en el Distrito Federal. Un punto de vista legal”, en Diálogo y Debate de Cultura Política (juliodiciembre).

Páginas web:

http://gaceta.diputados.gob.mx/SIL/Iniciativas/Base.html

http://www.diputados.gob.mx/LeyesBiblio/ref/cpeum_crono.htm 